\title{
Health Students Perception of Online Learning Environment during the COVID-19 Pandemic: Survey on Quality of Online Learning in Indonesian University
}

\author{
Ummu Artha Tsary Rumalessin ${ }^{1}$, Johanes Pramana Gentur Sutapa ${ }^{2}$ and Wisjnu Martani ${ }^{3}$ \\ ${ }^{1}$ Department of Higher Education Management, University of Gadjah Mada \\ Yogyakarta, Indonesia \\ ${ }^{2}$ Department of Forestry, University of Gadjah Mada \\ Yogyakarta, Indonesia \\ ${ }^{3}$ Department of Psychology, University of Gadjah Mada \\ Yogyakarta, Indonesia \\ *Corresponding author's email: ummu.artha.tsary [AT] mail.ugm.ac.id
}

\begin{abstract}
The COVID-19 pandemic has disrupted the teaching and learning process at various universities, especially for health science students. Electronic learning (E-Learning) is applied as a core learning method to carry out learning during the pandemic. This study aimed at investigating health science students' perception about the quality of their online learning during the pandemic. A mixed method research design was implemented in this current study. The modified version of Online Learning Environment Survey (OLES) was used as the main instrument to collect data from 390 health science students at 'Aisyiyah University in Yogyakarta consisting of seven study programs such as nursing, anesthesiology, midwifery, physiotherapy, nutrition, medical lab technology and radiology. Contrary assumption from the previous research, this study found that there were only slight differences between students from the seven study programs with regard to their perception of online learning. Majority of students agreed that during pandemic they have studied real cases and considered to be relevant to issues that occur outside the classroom. However, in health science education system where many courses are practical oriented, students confirmed that shifting completely to online mode may not be possible to enhance their skill to become a professional medical in the future. Therefore, it is prominent to design an effective curriculum for health science education system for the new normal.
\end{abstract}

Keywords-COVID-19, Online learning, learning environment, online learning environment survey (OLES)

\section{INTRODUCTION}

Since the beginning of 2020, the World Health Organization (WHO) has declared COVID-19 as a global pandemic. This situation has enforced higher education institution to do a transformation in regard to maintain learning process and to help slow the spread of COVID-19. As a result, higher education has moved to online electronic learning method, known as e-learning by utilizing hardware and software to substitute traditional way of learning instruction (face-to-face learning).

E-learning, known as online or virtual learning, is a learning method that integrates an internet connection [1]. This learning model is carried out by providing all distance learning courses exclusively via the internet [2]. Students can interact with lecturers and can access learning courses through the Learning Management System (LMS) used. To implement this learning model, universities are required to be able to apply appropriate teaching methods so as to create a positive learning environment. This by the reason of learning environment has been proven to have greatly impact on students' academic performance and their behavioral development. [3]-[5]. To determine the appropriate teaching strategy, lecturers cannot rule out the characteristics of students' disciplines [6], one of a complex disciplines in higher education is health science.

Health science is one of the disciplines that are considered more complex, demanding and full of pressure in preparing students to become medical personnel who have the ability in accordance with their own profession. Thus, the role of the learning environment greatly influences the student's learning experience [7]. The World Federation for 
Medical Education (WFME) have asserted that learning environment as one of the areas that must be targeted when evaluated educational programs in health disciplines [8]. Studies on education in the health sciences program have also proven that the learning environment is an important aspect that influences the attitudes, knowledge, skills, development and behavior of health science students, especially during pre-clinical years [9], [10]. Hence, learning environment in health science discipline needs to be concerned to ensure students learning outcomes, particularly during online learning.

Unlike universities elsewhere, Indonesian universities are relatively new in implementing this learning approach. Thus, the students had never experience any form of e-learning before the COVID-19 pandemic. This change has been seriously challenging for health science students at 'Aisyiyah University in Yogyakarta that has seven health study programs, they are nursing, anesthesiology, midwifery, physiotherapy, nutrition, medical lab technology and radiology. In the light of the large number of study program, the online learning environment must be able to provide a learning experience for students in order to master the knowledge and skills in their field. Studies of the online learning environment in the health disciplines have showed that students in the health disciplines find it difficult to interact during online learning. Bączek et al. (2020) revealed that online learning during the COVID-19 pandemic made students unable to interact properly with others students because the learning environment created was focused on text-based materials then boost student's active learning. Besides, lack of interaction with patients is definitely less effective in terms of increasing their clinical and social skills [11] [12]. Furthermore, communication and collaboration in the learning process are not established effectively so that the online learning environment that is created is still a problem, for that issue it is necessary to further identifies problems/obstacles in implementing an online learning environment. As health science are encourage to increase in-person delivery and priorities hands on skill-based learning[13], then their quality of online learning should be evaluated. Accordingly, this study aimed at investigating health science students' perception about the quality of their online learning during the pandemic.

\section{METHOD}

This present study used a mixed method design encompassing a questionnaire and interviews to gain profound concepts into the health students' perception toward their quality of online learning. This study was conducted with the health students from different study program who were enrolled in health faculty at University of 'Aisyiyah Yogyakarta, Indonesia. The students sample comprised 390 sample in total, consisting of 64 physiotherapy students $(\mathrm{n}=64), 63$ nursing students $(n=63), 60$ medical lab technology students $(n=60), 58$ anesthesiology students $(n=58), 55$ nutrition students $(n=55), 50$ midwifery students $(n=50)$ and 50 radiology students $(n=50)$. All students participating in this study were all undergraduate students coming from all academic years. Their ages are between 17-24 years old.

To collect the data, Online Learning Environment Survey (OLES) developed by Trinidad et al., (2005) dan Yee (2013) [14], [16] was adapted in this study with some modifications to fit the context of the current research setting. The survey consisted of eleven OLES scales (one of which was added by the researcher to be adjusted based on the Indonesian education context). All scales were used to investigate the students' perceptions on online learning environment. The modified version of OLES contained a total of 46 items broken into eleven scales - AL (Authentic Learning), PR (Personal Relevance), SA (Student Autonomy), EA (Evaluation \& Assessments), LS (Lecturer Support), SIC (Student Interaction \& Collaboration), PC (Professional Competence), EN (Enjoyment), AS (Asynchronous), OLT (Online Learning Tools) and ID (Interface Design). The questionnaire has 5 point Likert scale (1-Never; 2-Sometimes; 3 Quite Often; 4-Frequently; and 5-Always) was used to gather students' responses. To facilitate the collection and analysis of data derived from the survey, the eleven modified OLES scales were clustered into three categories: Quality of Learning, Support for Learning, and Usability of the Online Learning Tools.

In this paper, the Quality of Learning category will be reported. In order to adequately address perceptions about quality of learning in an online learning environment, the students in the study were asked to complete the Authentic Learning (AL), Personal Relevance (PR), Student Autonomy (SA) and Evaluation \& Assessments (EA). The collected data was analyzed via ANOVA to investigate the differences between the health students from seven study program toward their quality of learning in an online learning environment during COVID-19 pandemic, and then describe their perspectives of it. To elicit more understanding, the feedback on the semi structure interview session was also analyzed via thematic analysis.

\section{RESULT}

Table 1 show there were no statistically significant differences at the $(\mathrm{p} \geq 0.05)$ level in the means between health students (nursing, anesthesiology, midwifery, physiotherapy, nutrition, medical lab technology and radiology) on the four scales associated with the Quality of Learning category: Authentic Learning, Personal Relevance, Student Autonomy and Evaluation \& assessment. The effect sizes were also small-medium (less than 0.2)[17].

In the Quality of Learning category, Student Autonomy had the highest means among all four scales $(\mathrm{M}=3.98$ for Nursing, $M=4.01$ for Anesthesiology, $M=4.19$ for Midwifery, $M=4.00$ for Physiotherapy, $M=4.15$ for Nutrition, $M=4.03$ for Medical lab technology and M=3.94 for Radiology). However, Evaluation \& assessments scale had the lowest means 
( $M=3.48$ for Nursing, $M=3.53$ for Anesthesiology, $M=3.78$ for Midwifery, $M=3.41$ for Physiotherapy, $M=3.53$ for Nutrition, $M=3.47$ for Medical lab technology and $M=3.26$ for Radiology).

Table 1: Mean for Authentic Learning (AL), Personal Relevance (PR), Students Autonomy (SA) and Evaluation \& Assessment (EA)

\begin{tabular}{|c|c|c|c|c|c|c|c|c|c|c|}
\hline \multirow{3}{*}{$\begin{array}{l}\text { OLES } \\
\text { Scales }\end{array}$} & \multicolumn{7}{|c|}{ Descriptive statistic } & \multicolumn{3}{|c|}{ Differences } \\
\hline & \multicolumn{7}{|c|}{ EMean } & \multirow{2}{*}{$\begin{array}{c}\text { Effect } \\
\text { size }\end{array}$} & \multirow[t]{2}{*}{$\mathbf{F}$} & \multirow{2}{*}{$\underset{\text { value }}{p}$} \\
\hline & Nursing & Anesthesiology & Midwifery & Physiotherapy & Nutrition & MLT & Radiology & & & \\
\hline $\mathrm{AL}$ & 3.82 & 3.86 & 3.98 & 3.88 & 3.70 & 3.76 & 3.52 & 0.01 & 2.16 & 0.32 \\
\hline PR & 3.81 & 3.72 & 4.04 & 3.84 & 3.92 & 3.79 & 3.40 & 0.03 & 2.98 & 0.06 \\
\hline SA & 3.98 & 4.10 & 4.19 & 4.00 & 4.15 & 4.03 & 3.94 & 0.31 & 2.04 & 0.05 \\
\hline EA & 3.48 & 3.53 & 3.78 & 3.41 & 3.53 & 3.47 & 3.26 & 0.01 & 0.96 & 0.45 \\
\hline
\end{tabular}

Fig. 1 shows that there were approximately equal means for the five items in the Authentic Learning scale that fall under the "Frequently" category. These scores indicate that Nursing, Anesthesiology, Midwifery, Physiotherapy, Nutrition, Medical lab technology and Radiology students perceived that authentic learning was an important factor in their quality of online learning. Students perceived that during the online learning process, it is important to have learning courses that are in accordance with real problems as part of their learning activities during the COVID-19 pandemic.

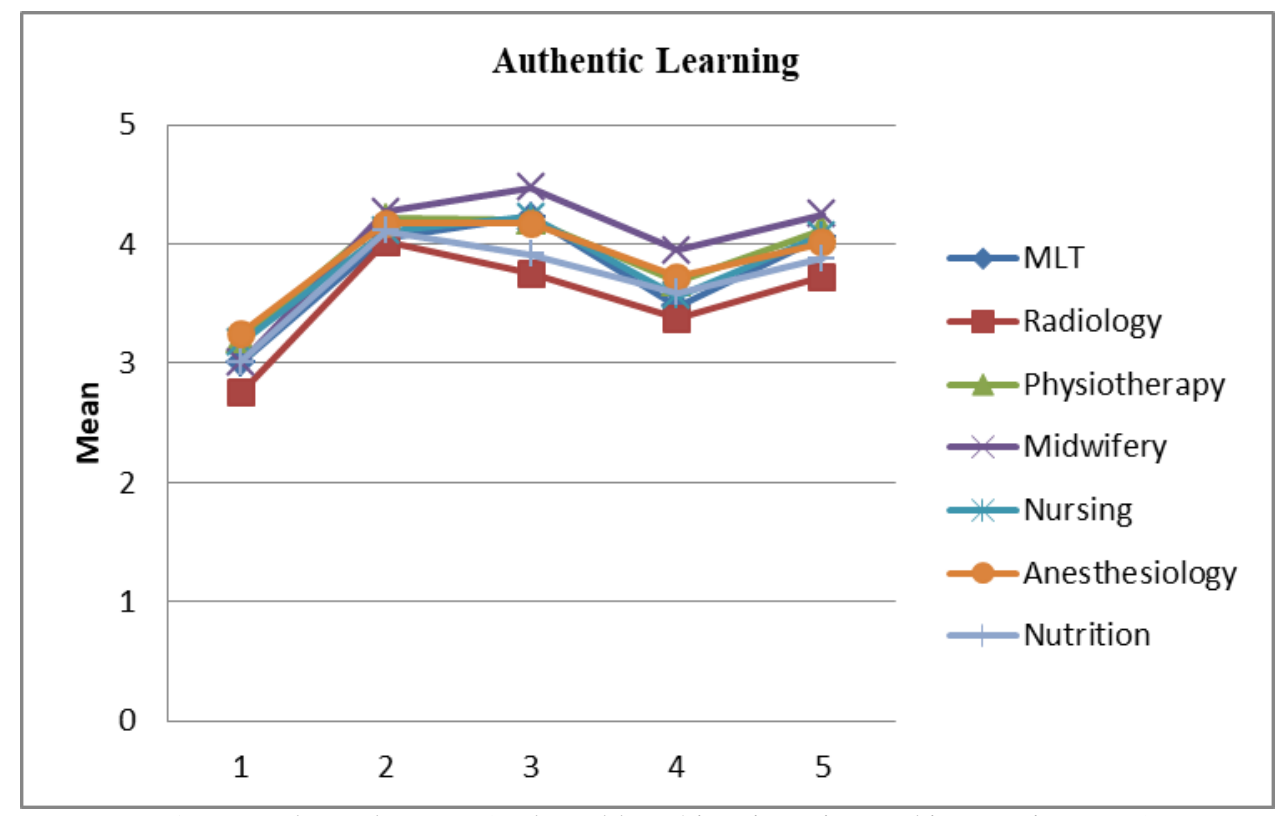

1. I study real cases (real problems/situations in working environment) related to the class activities.

2. I use real facts in class activities.

3. I work on assignments that deal with real-world information.

4. I work with real examples.

5. I apply real world experience to the topic of study.

Figure 1: Means of individual items in Authentic Learning (AL) scale

Most individual items in the Personal Relevance scale also fell under the "Frequently" category (Fig. 2). Midwifery students seemed to have scored higher in item three, agreeing that they can apply their everyday experience related to the topic being studied. On the other hand, Radiology students seemed to score the lowest in that particular item. This indicates that Radiology students perceived that they seldom applied their everyday experience as part of their classroom activities. 


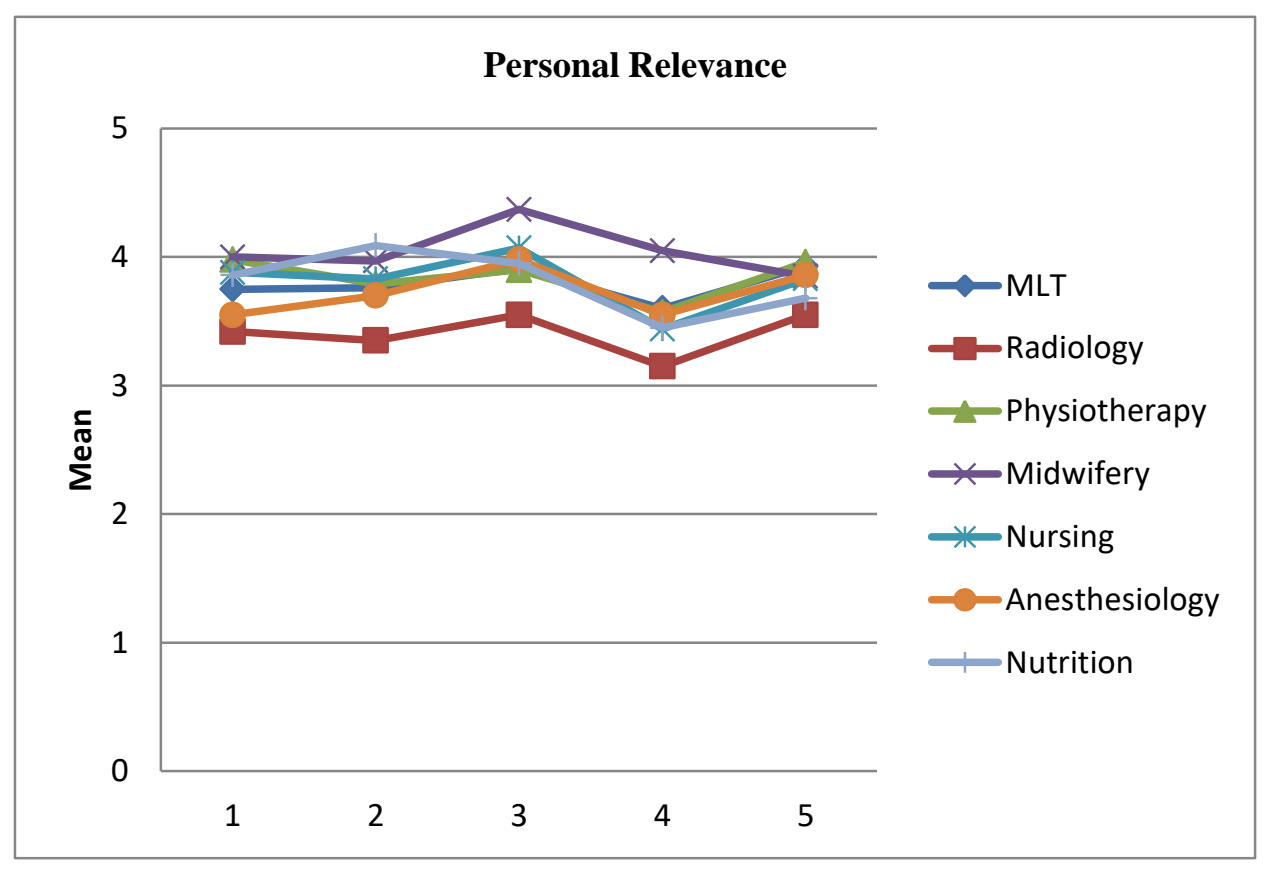

1. I can relate what I learn to my life outside of this class.

2. I am able to pursue topics that interest me.

3. I apply my everyday experiences in class.

4. I link class work to my life outside of this class.

5. I learn things about the world outside of this class.

Figure 2: Means of individual items in Personal Relevance (PR) scale

All five items in the Student Autonomy scale fell in the "Frequently" category (see Fig. 3). This indicates that the students perceived that they were able to control their own learning in the online learning. Whether nursing, midwifery, physiotherapy, anesthesiology, MLT, nutrition and radiology students are scored equally high on item one and two, agreeing that students need to learn by themselves so as to comprehend the courses. Nonetheless, MLT students seemed to have the lowest score of all students in item four. This indicates that students feel unmotivated in an online learning.

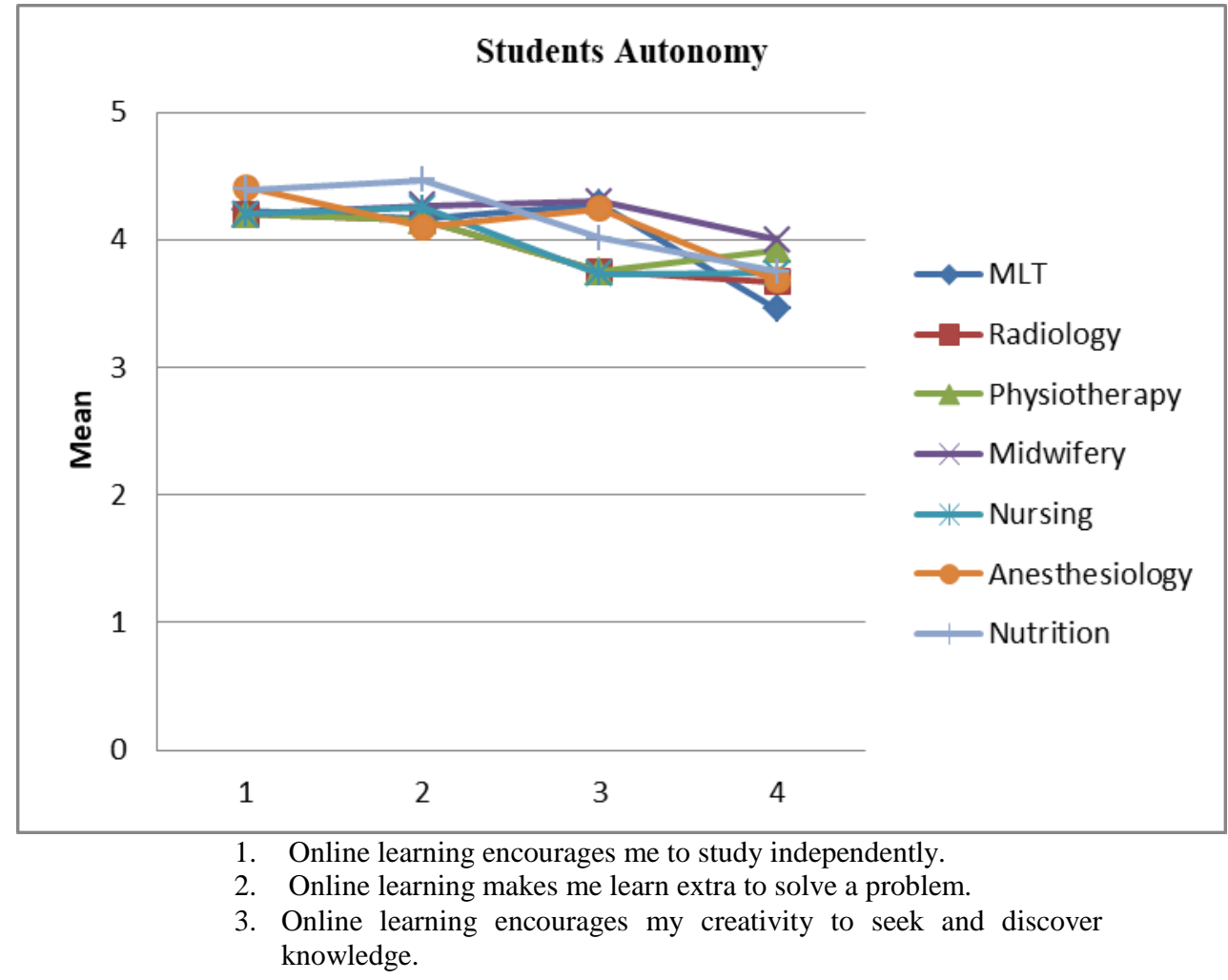


4. Online learning encourage my motivation to attend lectures

Figure 3: Means of individual items in Students Autonomy (SA) scale

As drawing out in Fig. 4, item one and two had the highest mean among all the items in the Evaluation \& Assessments scale. This shows that students' preferred varied types of assignment form than solely one specific form, thus both individual and group assignment are preferable during COVID-19 pandemic. On the other hand, item four seems to have the lowest score of all items. As showed that all students have different perceptions. Radiology students had the lowest score (mean=2.50) compared to students from other study programs. It was noted that Radiology student rarely get feedback from the lecturers on the assignments/tests they do.

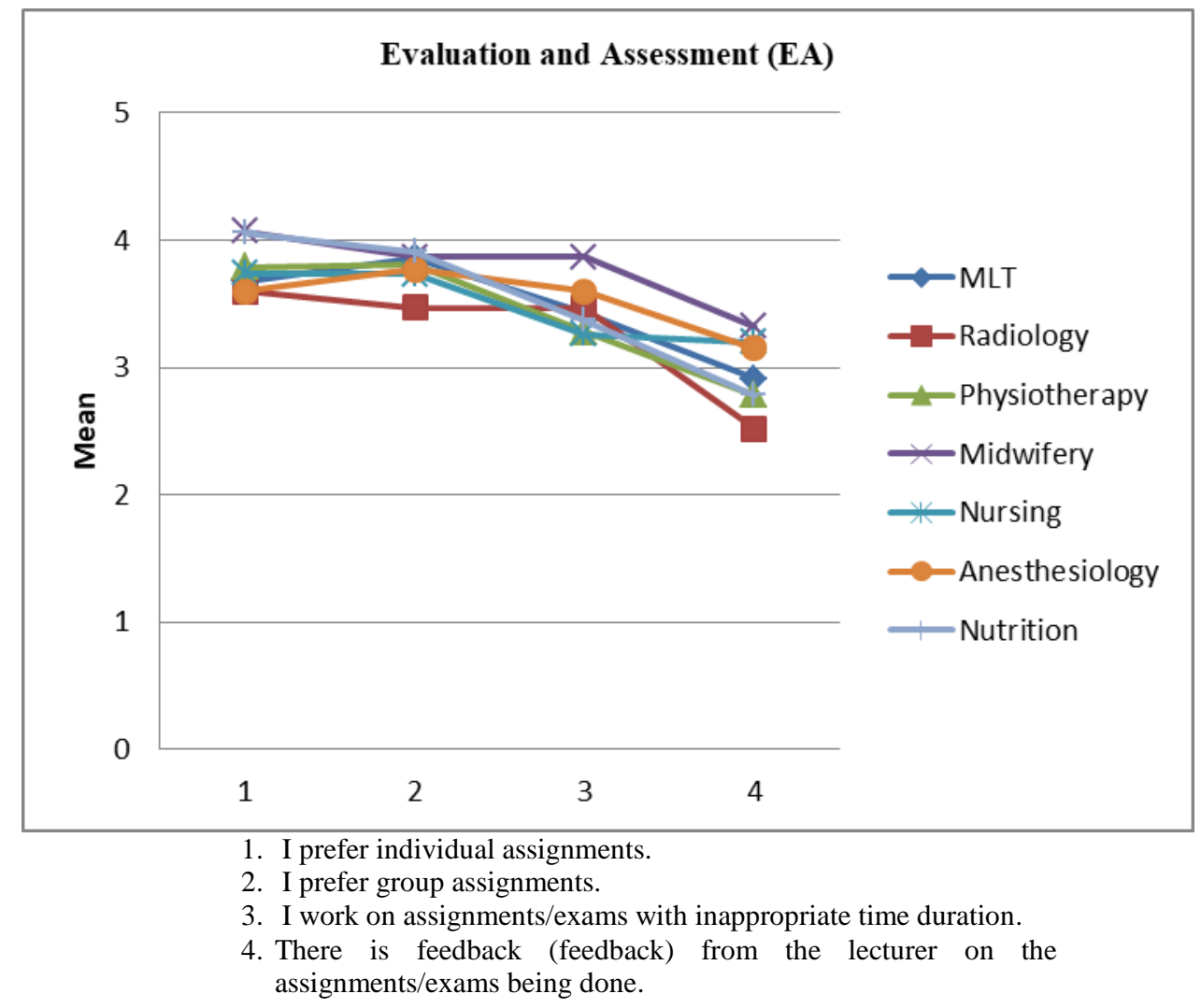

Figure 4: Means of individual items in Evaluation \& Assessments (EA) scale

These results will then be further investigated, many of these factors emerged during the qualitative analysis of the data from interviews. Four themes emerged from the qualitative analysis from the Authentic Learning, Personal Relevance, Student Autonomy and Evaluation \& Assessments Scales. Two of these themes were positive: Learning based on Real-life experiences/examples and improving learning management. However, two negative themes in respect to the quality of learning emerged from the analysis- Lack of motivation and the lack of feedback from the lecturers.

\subsection{Learning based on Real-life Experience/Example}

The findings of qualitative data discovered that students felt that during online learning, they often studied and worked on assignments that dealt with real cases related to the current problems in the community with respect to the health issues. Students were asked to discuss with their peers about one particular case given, then were asked to identify the case, how the examination actions should be carried out, then presenting the result. In addition, students tend to have perception that they were able to apply real-world experiences in accordance with the topic of the courses being studied in the classroom through an appropriate example.

The learning courses are relevant, there are discussions about how medical examination that are often found in the hospital/community" (Midwifery Student)

"During online learning, we are often hold discussions and work on group assignment to identify and examine certain cases given by the lecturer" (Anesthesiology Students). 
"In my opinion what makes online learning interesting is that during tutorials, we often examine disease problems that occur in the community, we analyze how they cause it, what actions must be taken to examine it, etc, especially those related to viruses. I think it is very relevant with the current situation for us" (MLT Students)

\subsection{Improve Learning Management}

Due to the limited time in synchronous learning, then majority of the students in all study programs at university of 'Aisyiyah Yogyakarta revealed that the online learning trained them to be able to manage their learning well, how students independently had to be able to comprehend learning courses given. Students also perceived that online learning requires them to be responsible for their own learning, both theoretical and practical understanding.

For theoretical subjects, of course, with online learning, I have to explore more by myself to have better understanding because studying in class is not enough" (Physiotherapy Students)

"This learning model makes me have to manage my time very well so that I can recall my mind about particular courses that I did not understand while studying in class" (Nursing Students)

\subsection{Lack of Motivation}

This theme emerged based on the results of quantitative analysis in which students felt unmotivated during their online learning. In their opinion, e-learning will certainly be bored if the lecturer keep applying monotonous ways of delivering courses. During COVID-19 pandemic, text-based material was the only way applied by their lecturer during elearning. Students perceived that it is definitely less effective in term of enhancing student's social skills. Consequently, students were less active during e-learning than during traditional classes. One of the reasons could be the lack of an interactive approach when developing e-learning courses.

"In my opinion, one of the reason students felt unmotivated during e-learning is in the way of teaching approach used by the lecture, because I only listen to lecture and read the material for the whole class, so I get bored, and somehow I don't understand the courses because no discussion or ask a question in such a short time." (Nutrition Students)

"Online learning is quite difficult to comprehend the courses, even though I can learn via books, video or any references given by the lecturer. Yet, as a health student, we need to deepen the courses because it is really new science. By applying teacher-centered, I do not think it is effective to apply e-learning for the whole period" (Nursing Students).

On the other hand, as health science are encouraged to increase and priorities hands on skill-based learning, students prefer face-to-face learning to improve their clinical skills rather than e-learning. This statement was raised due to the elearning is ineffective in improving their clinical skills. Students stated that during online learning in midst of COVID-19, students unable to interact with patients, incapable to do all practical skills with medical equipment therefore it is seems to be inferior for teaching practical skills by e-learning.

"Practical teaching is inefficient in online learning, because lecturers only sends videos obtained from any platform on the internet as a media for practical courses, it is less efficient if we only watch videos without getting an explanation from our instructor for further understanding and doing experiment like we used to at laboratory with robot, etc " (Midwifery Students)

"The most difficult thing during e-learning is in practical courses. If we only watch videos, obviously it is inefficient. As a medical personnel, we have to get involve our skill with human, if we never had experience in doing certain skills related to our profession before, then it might be dangerous for our patient's life later, or we might be in danger as well." (Radiology Students)

\subsection{Lack of Feedback}

Apart from the lack of motivation, students also have negative perception of the quality of online learning due to the lack of feedback from lecturers on the assignment they were doing. This result is in harmony with the findings of the quantitative analysis on the evaluation and assessment scale in item four which shows the lowest score, especially for Radiology students that had the lowest score (mean=2.50). These results were confirmed further from interview.

The findings of the qualitative analysis confirmed that students rarely received feedback on the tasks they were doing. The task is in a form of non-written assignments (discussion or questions and answers between fellow students). Students expressed that this negative perception arises because when discussion session take place with problem-solving scenarios or students are asked to ask and answer each other about one particular topic/problem given, lecturers rarely provide further feedback at the end of the session. Therefore, students do not know whether what has been discussed is correct or not. 


\begin{abstract}
"During tutorial when discussing certain cases, lecturers do supervise, but rarely provide feedback after the session end, whether what the students discussed was true or not, it is better to have justification." (MLT Students)
\end{abstract}

\title{
6. DISCUSSION
}

The COVID-19 pandemic has affected all levels of health science from in-person didactics and clinical rotation. To our knowledge, this is the first study to assess health students' online learning environment amid the COVID-19 pandemic (not only medical students). The purpose of this study was to explore the health students' perception toward online learning environment in term of quality of online learning. In addition, this study also aimed at examining the difference between students perception among different study programs at health science at University of 'Aisyiyah Yogyakarta. Many previous researchers have identified that the students at different discipline has different perception with respect to the e-learning. However, the findings of this study argued that there is no significantly perception of quality of online learning among different study programs at health science (nursing, anesthesiology, midwifery, physiotherapy, nutrition, medical lab technology and radiology). Our findings demonstrated that different level of study program among health science discipline does not have great influence to the quality of online learning. Pertaining to learning perspectives, health students perceived that it is such a crucial point to maintain courses contents authentically during e-learning for the convenience and motivate students to study real problems since health disciplines prefer cases that are more "real" than ready-made aquifer cases [18][19]. This finding is unswerving with an empirical test in an Agricultural science where the researcher found that course contents was the major determinants for smooth conduct of online classes [20]. Specifically in terms of course contents, it should be well structured, concise, interactive and relevant, then learning was enhanced [21]. In addition, online learning environment for health science has to be able to provide clear and relevant learning with students' personal experiences so as to have a concrete understanding of the theory and the practical learning [21].

Most respondents qualitatively reported positive perceptions of the quality of online learning during the pandemic, noting knowledgeable relevant content, the ability to discuss, ask questions and self-studied management. These findings may not be unexpected as health education system in Indonesia has been transitioning to contextual curricula for more than a decade, particularly during pre-clinical years. However, health students reported considerably less favorable perception of their quality of online learning compared with traditional classes. We attribute this finding to the timing of our interview. Although e-learning is one of the greatest learning approaches applying during pandemic, many students expressed their concern and frustration about lack of feedback from lecturer and ineffective teaching method used for theoretical and practical teaching. Of concern was the appropriate teaching method to boost interactivity of online learning, if possible, instead of using text-based materials, video instruction by lecture seems to be superior in teaching practical skills. In this model, the lecturer conducts a demonstration, and then he repeats the procedure demonstrated, this time describing all necessary sub-steps (deconstruction) [11]. Following this, the student has to explain each sub-step while the teacher follows the student's instructions (comprehension). This model was also in consonance with the concept of experience-based learning in online clinical training at the University of Hong Kong which was formulated by lecturers and instructors who specifically teach online practical courses for nursing students during the COVID-19 pandemic to guarantee student learning experience[22]. The study revealed that in order to provide a learning experience in practical courses for nursing that is able to improve cognitive abilities and critical thinking during clinical period; the flipped-learning method is used to carry out online practical courses. As for the implementation procedure, students are first asked to read (pre-reading) and then will be given a quiz, this session is vital to increase self-awareness of learning needs[23]. During synchronous lectures, clinical scenarios are made in the form of clinical cases or problems to illustrate the clinical relevance of the subject matter being taught by requiring students to identify these clinical problems and plan nursing care through mini quizzes. Clinical cases are designed to describe disease manifestations, nursing assessments and observations so as to further strengthen cognitive processes in learning [11]. Then, constructive feedback on their performance will be given immediately to correct misunderstandings and to optimize the learning environment which encourages questions and dialogue from students. After that, a pragmatic approach was involved by using two lecturers/instructors to demonstrate nursing care in a simulated clinical environment.

In short, it is emphasized that the learning concept is very important for student skills in order to generate interest in learning and to strengthen cognitive processes in the integration and application of knowledge during e-learning [22]. The technique described above is associated with higher learning outcomes, mostly concerning increasing knowledge and clinical reasoning.

\section{CONCLUSION}

COVID-19 pandemic has shifted completely to online mode, then learning process at university is also conducted virtually. It is important to note that our survey was conducted in the amidst of COVID-19 pandemic to assess quality of online learning for health students, therefore this may not be fully comprehended for every details in health science education system. It is known that online learning has enable the continuation of health education during these unpredicted times. Moving forward from this pandemic, in order to maximize the benefits of online learning and to 
enhance the efficacy of health education in the future, it is notably for lecture and university to implement teaching formats such as problem-based learning in order to create active learning. The findings in this study allowing practitioners to digest information to develop online learning by taking into consideration students' perspective. As in health science education system where many courses are practical oriented, it is prominent to design an effective curriculum for health science online education system for the new normal to enhance students' skill to become professional medical in the future.

\section{ACKNOWLEDGEMENT}

The researchers would like to convey their gratitude to Department of Higher Education and Management University of Gadjah Mada and all parties that have taken a part in accomplishing this research.

\section{REFERENCES}

[1] C. M. Chiu, C. S. Chiu, and H. C. Chang, "Examining the integrated influence of fairness and quality on learners' satisfaction and Web-based learning continuance intention," Inf. Syst. J., vol. 17, no. 3, pp. 271-287, 2020, doi: 10.1111/j.1365-2575.2007.00238.x. https://onlinelibrary.wiley.com/doi/abs/10.1111/j.13652575.2007.00238.x

[2] T. Nguyen, "The Effectiveness of Online Learning: Beyond No Significant Difference and Future Horizons," MERLOT J. Online Learn. Teach., vol. 11, no. 2, pp. 309-319, 2015. https://jolt.merlot.org/Vol11no2/Nguyen_0615.pdf

[3] J. M. Genn, "AMEE Medical Education Guide No. 23 (Part 2): Curriculum, environment, climate, quality and change in medical education - A unifying perspective," Med. Teach., vol. 23, no. 5, pp. 445-454, 2001, doi: 10.1080/01421590120075661. https://scirp.org/reference/referencespapers.aspx?referenceid=1344554

[4] R. M. Harden, "The learning environment and the curriculum," Med. Teach., vol. 23, no. 4, pp. 335-336, 2001, doi: 10.1080/01421590120063321. https://www.tandfonline.com/doi/abs/10.1080/01421590120063321

[5] S. Roff and S. McAleer, "What is educational climate?," Med. Teach., vol. 23, no. 4, pp. 333-334, 2001, doi: 10.1080/01421590120063312. https://www.tandfonline.com/doi/abs/10.1080/01421590120063312

[6] M. A. Sunkad, S. Javali, Y. Shivapur, and A. Wantamutte, "Health sciences students' perception of the educational environment of KLE University, India as measured with the Dundee Ready Educational Environment Measure (DREEM)," J. Educ. Eval. Health Prof., vol. 12, p. 37, 2015, doi: 10.3352/jeehp.2015.12.37. https://pubmed.ncbi.nlm.nih.gov/26268829/

[7] L. M. Tompodung, "Persepsi mahasiswa terhadap lingkungan pembelajaran di Universitas Sam Ratulangi Manado," J. e-Biomedik, vol. 5, no. 2, 2017, doi: 10.35790/ebm.5.2.2017.17072.

[8] The Executive Council WFME, "Global Standards for Basic Medical education The 2012 Revision," World Fed. Med. Educ., p. 46, 2012.

https://www.researchgate.net/publication/255172274_Book_WFME_Global_Standards_for_Basic_Medical_Edu cation_-_the_2012_Revision_Reference_book_available_from_WFME_website_httpwwwwfmeorgnewsgeneralnews263-standards-for-basic-medical-education-the-2012-r

[9] S. S. Mayya and S. Roff, "Students' perceptions of educational environment: A comparison of academic achievers and under-achievers at Kasturba Medical College, India," Educ. Heal., vol. 17, no. 3, pp. 280-291, 2004, doi: 10.1080/13576280400002445. https://manipal.pure.elsevier.com/en/publications/students-perceptionsof-educational-environment-a-comparison-of-a

[10] S. J. Wayne, S. A. Fortner, J. A. Kitzes, C. Timm, and S. Kalishman, "Cause or effect? The relationship between student perception of the medical school learning environment and academic performance on USMLE Step 1," Med. Teach., vol. 35, no. 5, pp. 376-380, 2013, doi: 10.3109/0142159X.2013.769678. https://pubmed.ncbi.nlm.nih.gov/23444883/

[11] M. Bączek, M. Zagańczyk-Bączek, M. Szpringer, A. Jaroszyński, and B. Wożakowska-Kapłon, "Students' perception of online learning during the COVID-19 pandemic: a survey study of Polish medical students," pp. 114, 2020, doi: 10.21203/rs.3.rs-41178/v1. https://www.ncbi.nlm.nih.gov/pmc/articles/PMC7899848/

[12] M. H. Rajab and M. Soheib, "Privacy Concerns Over the Use of Webcams in Online Medical Education During the COVID-19 Pandemic," Cureus, vol. 13, no. 2, pp. 2-9, 2021, doi: 10.7759/cureus.13536. https://www.ncbi.nlm.nih.gov/pmc/articles/PMC7996672/

[13] M. Ratnaweera and R. Khareedi, "Teaching and learning during COVID 19: Perspectives of undergraduate Oral Health students.," Asian J. Educ. e-Learning, vol. 9, no. 5, pp. 90-95, 2021, doi: 10.24203/ajeel.v9i5.6735. https://www.researchgate.net/publication/355914929_Teaching_and_learning_during_COVID_19_Perspectives_ of_undergraduate_Oral_Health_students

[14] S. Trinidad, J. Aldridge, and B. Fraser, "Development, validation and use of the Online Learning Environment Survey,” Australas. J. Educ. Technol., vol. 21, no. 1, pp. 60-81, 2005, doi: 10.14742/ajet.1343. https://ajet.org.au/index.php/AJET/article/view/1343

[15] R. Yee, "Perceptions of Online Learning in an Australian University: An International Students' (Asian Region) Perspective - Quality of Learning," Int. J. e-Education, e-Business, e-Management e-Learning, vol. 3, no. 2, 
2013, doi: 10.7763/ijeeee.2013.v3.206.

[16] R. C. S. Yee, "Perception of Online Learning in an Australian University: Malaysian Student's Perspectives," PhD Dissertation. pp. 1-263, 2011.

[17] J. Cohen, STATISTICAL POWER ANALYSIS for the BEHAVIORAL SCIENCES, 2nd ed. New York: Lawrence Erlbaum Associates, 1988.

[18] G. Franklin et al., "How the COVID-19 pandemic impacted medical education during the last year of medical school: A class survey," Life, vol. 11, no. 4, pp. 1-17, 2021, doi: 10.3390/life11040294. https://www.ncbi.nlm.nih.gov/pmc/articles/PMC8065402/

[19] S. Dost, A. Hossain, M. Shehab, A. Abdelwahed, and L. Al-Nusair, "Perceptions of medical students towards online teaching during the COVID-19 pandemic: A national cross-sectional survey of 2721 UK medical students," BMJ Open, vol. 10, no. 11, pp. 1-10, 2020, doi: 10.1136/bmjopen-2020-042378. https://bmjopen.bmj.com/content/bmjopen/10/11/e042378.full.pdf

[20] T. Muthuprasad, S. Aiswarya, K. S. Aditya, and G. K. Jha, "Students' perception and preference for online education in India during COVID -19 pandemic," Soc. Sci. Humanit. Open, vol. 3, no. 1, p. 100101, 2021, doi: 10.1016/j.ssaho.2020.100101. https://www.ncbi.nlm.nih.gov/pmc/articles/PMC7836920/

[21] E. W. Villanueva, H. Meissner, and R. W. Walters, "Medical Student Perceptions of the Learning Environment, Quality of Life, and the School of Medicine's Response to the COVID-19 Pandemic: A Single Institution Perspective," Med. Sci. Educ., vol. 31, no. 2, pp. 589-598, 2021, doi: 10.1007/s40670-021-01223-z. https://pubmed.ncbi.nlm.nih.gov/33585071/

[22] M. M. K. Chan, D. S. F. Yu, V. S. F. Lam, and J. Y. H. Wong, "Online clinical training in the COVID-19 pandemic," Clin. Teach., vol. 17, no. 4, pp. 445-446, 2020, doi: 10.1111/tct.13218. https://pubmed.ncbi.nlm.nih.gov/32643184/

[23] L. Childs-Kean, M. E. E. Mlis, and M. D. Smith, "Use of learning style frameworks in health science education," Am. J. Pharm. Educ., vol. 84, no. 7, pp. 1-9, 2020, doi: 10.5688/ajpe7885. https://pubmed.ncbi.nlm.nih.gov/32773837/ 